\title{
The Red Wolf is Not a Hybrid
}

\section{RONALD M. NOWAK}

Office of Scientific Authority Mail Stop 725, Arlington Square

U.S. Fish and Wildlife Service

Washington, DC 20240, U.S.A.

The red wolf (Canis rufus), an endangered species that was extirpated in its original range in southeastern North America by 1970, was recently reintroduced successfully in North Carolina (Henry 1992; Parker \& Phillips 1991; Phillips \& Parker 1988). Simultaneously, a longstanding interest in its systematic status intensified as Wayne and Jenks (1991), on the basis of an analysis of mitochondrial DNA, proposed that at some time in the past the red wolf had originated as a hybrid between the gray wolf (Canis lupus) and the coyote (Canis latrans). They also held that the mtDNA component of the current red wolf population is predominantly coyote. Their conclusions, while questioned even from the standpoint of genetics (Dowling et al. 1992), have received widespread attention (Begley et al. 1991; DeBlieu 1992; O'Brien \& Mayr 1991).

That $C$. rufus and $C$. latrans had indeed hybridized was suspected long ago (Goldman 1944) and was generally considered one of the major factors in the near disappearance of the red wolf (McCarley 1962; Nowak 1979). However, it also was thought that this process was the result of modern human environmental disruption and that hybridization did not engulf the entire red wolf population prior to conservation efforts. The critical new suggestions made by Wayne and Jenks (1991) are: (1) that the red wolf actually originated as a hybrid and had never been a valid species or subspecies; and (2) that the existing captive and reintroduced red wolf population is substantially coyote in ancestry.

The study by Wayne and Jenks follows closely on reports of another "hybrid zone" in the Great Lakes region, said to involve the spread of coyote mtDNA to 62 percent of gray wolves in Minnesota and to 100 percent of those on Isle Royale (Lehman et al. 1991). Observations by field personnel in those areas, however, indicate no change in the morphological, behavioral, or ecological characters of the wolves (L.D. Mech \& R.O. Peterson, personal communication). Therefore, even if the mtDNA situation has been reported accurately for both the gray wolf and the current red wolf population, the latter still could retain all other characters of the original species, and thus not represent a hybrid zone in the usual sense. Indeed, Wayne and Jenks support continued protection of the red wolf.

Unfortunately, a likely typical reaction is that of Gittleman and Pimm (1991), who combined Wayne and Jenks' study with a background of their own to criticize efforts being made to reestablish the red wolf. They implied that this animal's "unusually modern discovery" in 1851 somehow supports a view that it is not distinctive. Actually, 1851 only marks the first publication of a valid scientific name for the animal. Its presence had been recognized long before, published under another name in 1791, based on observations in 1774 (Harper 1942). The coyote, the distinctiveness of which is unquestioned, was not named until 1823, based on observations in 1819 (Young \& Jackson 1951). Contrary to what is stated by Gittleman and Pimm (1972), the red wolf was not "resurrected as a species in 1972, by Paradiso and Nowak." Most authors have accepted specific status since the studies of Goldman $(1937,1944)$. Such workers included Ferrell et al. (1980), who were incorrectly cited by Gittleman and Pimm as not having found the red wolf to be distinctive. There was a minority view that the red wolf is a subspecies of the gray (Lawrence \& Bossert 1967, 1975), but until 1991 there was only one published suggestion of hybrid origin (Mech 1970) and it was unsupported by study.

Gittleman and Pimm suggested that if the red wolf is not a full species it may not be worth saving. However, the Endangered Species Act of 1973 also covers subspecies and certain vertebrate populations. Of the 49 native United States terrestrial mammals now on the List of Endangered and Threatened $W$ ildlife, $\mathbf{3 8}$ are subspecies or populations; they include such entities as the Key deer, the Mount Graham red squirrel, and the conterminous U.S. populations of the gray wolf and grizzly bear. The Endangered Species Act does not address hy. 
brids, but recent interpretations indicate that a species may continue to be covered, even if it has experienced limited genetic introgression from another species (Henry 1992; Refsnider 1990).

Wayne and Jenks considered the plausible view that the red wolf is a subspecies of the gray, but rejected it in favor of hybrid origin. The latter notion is unsupported by a large series of modern museum specimens (Nowak 1979). Had the red wolf always represented nothing more than a hybrid zone between gray wolf and coyote, we would expect a complete blend of all three named species throughout the designated range of the red wolf. However, specimens from approximately 1890-1930 suggest that hybridization was then just getting underway in the region where the western part of the red wolfs range met the southeastern part of the coyote's (Nowak 1979). In most of the region the two species were then sympatric or in close proximity, with hybrid individuals having appeared at a few restricted localities. Only in central Texas was there a substantial hybrid zone, where $C$. latrans and $C$. rufus (but not the sympatric $C$. lupus) blended into one another.

It could be argued, in an attempt to resolve the matter, that long ago the gray wolf and coyote did interbreed in southeastern North America, and that a resulting hybrid population subsequently stabilized and became reproductively isolated from its parental species. C. rufus would then be considered a valid species but one of hybrid origin. Such taxa are relatively common among plants and have been discovered among fishes (DeMarais et al. 1992), but have not been reported for mammals. Fossil history does not support this origin for $C$. rufus The red wolf, in much the same form as now, was present in North America through the Irvingtonian and Rancholabrean ages (Nowak 1979). It seems to represent an intermediate, surviving stage in the course of wolf evolution from a small coyote-like ancestor to the modern gray wolf. As already noted, hybridization with the coyote did occur, but only within the last $\mathbf{1 0 0}$ years or so.

Material collected after 1930 shows the spread of hybridization between $C$. rufus and $C$ latrans, and the steady reduction of unmodified red wolf populations (Nowak 1979). By the 1960s, such groups had largely disappeared, though available skulls from 1963-70 in extreme southeastern Texas indicate that the population there was still predominantly like original $C$. rufus. A number of animals subsequently were live-captured in that area and adjacent southwestern Louisiana, and used to form a breeding pool for eventual reintroduction.

I recently carried out a canonical discriminant analysis of measurements of relevant skulls, using the Statistical Analysis System (SAS Institute 1987). Three known groups were used: 50 coyotes of the subspecies $C$. la . trans lestes from before 1925 in Idaho, 38 gray wolves of the subspecies $C$. lupus pambasileus and $C$. l. tundrarum from Alaska, and 28 gray wolves of the subspecies $C$ l. lycaon from Minnesota and Isle Royale in the 1960 s and 1970s. In addition, 22 red wolves from before 1940 in Florida, Alabama, Mississippi, Louisiana, and the Big Thicket area of southeastern Texas were compared as individuals to the known groups. Also compared as individuals were 9 of the founders of the red wolf captive population and 5 of their descendants from the ongoing North Carolina reintroduction project. All series are composed only of complete skulls thought to represent full-grown males, and each series comprises every such specimen available from the indicated time and/or location. The pre-1940 red wolf sample is from a geographic and temporal range in the southeastern United States that previous work (Nowak 1979) suggests was not affected by hybridization with the coyote; no other appropriate specimens of wild Canis of any kind are available from this range. The 10 cranial measurements numbered, $1,2,4,5,6,8,11,12,14$, and 15 in my previous work (Nowak 1979) were entered into the analysis.

Graphical results (Fig. 1) show the three species- $C$. latrans, $C$. rufus, and C. lupus-to be distinct from one another. Minnesota and Isle Royale gray wolf populations have affinity to those of Alaska and are not indicative of hybridization with the coyote. The red wolf falls roughly between the coyote and gray wolf, but does not merge with either. The captive and reintroduced red

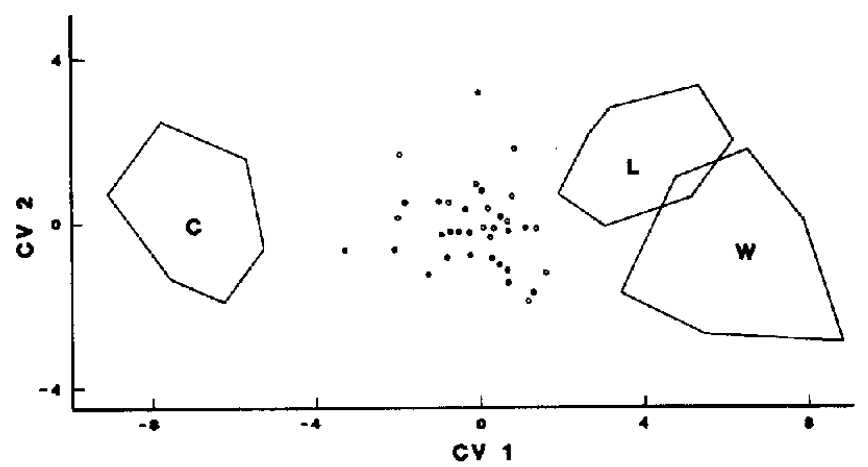

Figure 1. Plot of first and second canonical variables (CV 1 and $C V 2$ ) of a canonical discriminant analysis of skulls of Canis. Letters indicate mean positions of knoun groups: coyote (C), Minnesota and Isle Royale gray wolf (L) Alaska gray wolf $(W)$. Solid lines show boundaries of distributions of known groups. Dots indicate positions of 22 specimens of red wolf collected before 1940. Open circles indicate positions of 9 individuals used to found existing captive and reintroduced population of red wolf, and 5 individuals that bad been released in North Carolina. 
wolf stock has a statistical distribution close to that of the original $C$. rufus.

\section{Acknowledgments}

I am grateful to Lois Loges, David Waddington, and Jay Sheppard for assistance with computer work.

\section{Literature Cited}

Begley, S., L. Wilson, M. Hager, and P. Annin. 1991. Return of the wolf. Newsweek 118(7):44-50.

DeBlieu, J. 1992. Could the red wolf be a mutt? New York Times Magazine, 14 June:30-46.

DeMarais, B. D., T. E. Dowling, M. E. Douglas, W. L. Minckley, and P. C. Marsh. 1992. Origin of Gila seminuda (Teleostei: Cyprinidae) through introgressive hybridization: implications for evolution and conservation. Proceedings of the National Academy of Science 89:2747-2751.

Dowling, T. E., B. D. DeMarais, W. L. Minckley, and M. E. Douglas. 1992. Use of genetic characters in conservation biology. Conservation Biology 6:7-8.

Ferrell, R. E., D. C. Morizot, J. Horn, and C. J. Carley. 1980. Biochemical markers in a species endangered by introgression: the red wolf. Biochemical Genetics 18:39-47.

Gittleman, J. L., and S. L. Pimm. 1991. Crying wolf in North America. Nature 351:524-525.

Goldman, E. A. 1937. The wolves of North America. Journal of Mammalogy 18:37-45.

Goldman, E. A. 1944. Classification of wolves. Pages 389-636 in S. P. Young and E. A. Goldman, The wolves of North America. American Wildlife Institute, Washington, D.C.

Harper, F. 1942. The name of the Florida wolf. Journal of Mammalogy 23:339.

Henry, V. G. 1992. Finding on a petition to delist the red wolf (Canis rufus). Federal Register 57:1246-1250.

Lawrence, B., and W. H. Bossert. 1967. Multiple character analysis of Canis lupus, latrans, and familiaris, with a discussion of the relationships of Canis niger. American Zoologist 7:223232.
Lawrence, B., and W. H. Bossert. 1975. Relationships of North American Canis shown by a multiple character analysis of selected populations. Pages $73-86$ in $M$. W. Fox, editor, The wild canids, their systematics, behavior, ecology and evolution. Van Nostrand Reinhold, New York.

Lehman, N., A. Eisenhawer, K. Hansen, L. D. Mech, R. O. Peterson, P. J. P. Gogan, and R. K. Wayne. 1991. Introgression of coyote mitochondrial DNA into sympatric North American gray wolf populations. Evolution 45:104-119.

McCarley, H. 1962. The taxonomic status of wild Canis (Canidae) in the south central United States. Southwestern Naturalist 7:227-235.

Mech, L. D. 1970. The wolf: the ecology and behavior of an endangered species. Natural History Press, Garden City, New York.

Nowak, R. M. 1979. North American Quaternary Canis. Monograph No. 6. Museum of Natural History, University of Kansas, Lawrence, Kansas.

O'Brien, S. J., and E. Mayr. 1991. Bureaucratic mischief: recognizing endangered species and subspecies. Science 251:11871188.

Paradiso, J. L., and R. M. Nowak. 1972. Canis rufus. Mammalian Species. No. 22.

Parker, W. T., and M. K. Phillips. 1991. Application of the experimental population designation to recovery of endangered red wolves. Wildlife Society Bulletin 19:73-79.

Phillips, M. K, and W. T. Parker. 1988. Red wolf recovery: a progress report. Conservation Biology 2:139-141.

Refsnider, R. L. 1990 . Notice of finding on a petition to delist the gray wolf (Canis lupus). Federal Register 55:4865649659.

SAS Institute. 1987. SAS/STAT guide for personal computers. Version 6 edition. SAS Institute Inc., Cary, North Carolina.

Wayne, R. K, and S. M. Jenks. 1991. Mitochondrial DNA analysis implying extensive hybridization of the endangered red wolf, Canis rufus. Nature 351:565-568.

Young, S. P., and H. H. T. Jackson. 1951. The clever coyote. Wildlife Management Institute, Washington, D.C:

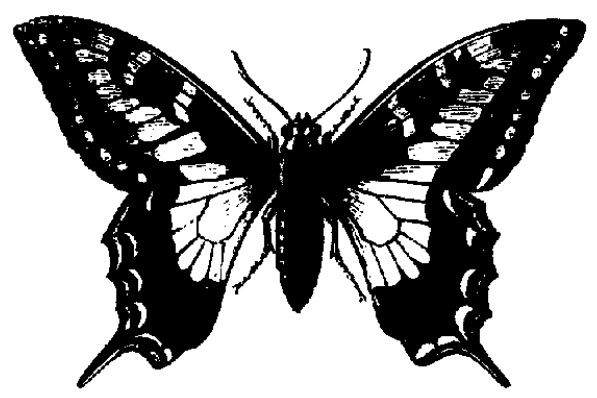

